\title{
A Study of Youth Badminton Players' Participation Motivation and Relate Elements*
}

\author{
Howard Z. Zeng ${ }^{1}$, Wen-Yan Meng ${ }^{2}$, Peng Sun ${ }^{3}$, Li-Sheng Xie ${ }^{4}$ \\ ${ }^{1}$ Brooklyn College of the City University of New York, USA \\ ${ }^{2}$ Education Research Institution of Jiangsu Province, Nanjing, PRC \\ ${ }^{3}$ College of Physical Education \& Health Care, East China Normal University, Shanghai, PRC \\ ${ }^{4}$ Changsu Foreign Language School, Changsu Jiangsu, PRC
}

\begin{abstract}
This study examined those essential factors truly motivated youth athletes taking-part in Badminton practices and competitions using the Adapted Questionnaire of Badminton Athlete's Motivation-Chinese Version $\left(A Q B A M^{-C V}\right)$. Participants were 87 youth badminton athletes (52 boys, 35 girls; age 13-17) from Jiangsu province, China. The AQBAM ${ }^{C V}$ contains three parts: the primary part asks: "What factors motivate you to take-part in badminton practices and competitions continually? " Eighteen motivation factors (MFs) were provided for participants to respond with a 5-points Likert type scale from 5-points "Strongly-agree" to 1-points "Disagree". Data analyses were through a 2 (boy or girl) $x 2$ (Middle-School or High-School) $x 2$ (SportSchool-Athlete or Tradition-Badminton-School-Varsity-Athlete) MANOVA. Results showed no significant difference in the 'Gender'; however, significant differences were found in 'School-Level'; and 'Athlete-Types'. Post hoc tests revealed that: among the 18 MFs comparisons, only MF6 "To contest winners" reached significant difference in 'School-Levels' with Middle-School scored higher than High-School. However, there were two motivation factors - MF9 "become professional player" and MF17 "become a coach" reached significant difference in 'Athlete-Types' with Sport-School-Athlete scored higher than the Tradition-BadmintonSchool-Varsity-Athlete. Results are discussed regarding with the differences and similarities about youth athletes' participation motivations between those previous studies and the current study.
\end{abstract}

Keywords: youth athlete, badminton, participation motivation, practices, competitions.

\section{Instruction}

The sport of badminton is one of the oldest games on the earth with more than 2,500 years history. Its root can track to two cultures, one was Chinese and the other was Indian. Modern badminton sport, however, receipted its name from Badminton House; locate in Gloucester, England [1]. Badminton is a racket sport for two or four people with a sequential structure characterized by actions of short duration and high intensity. In official badminton competition men's and women's singles, men's and women's doubles, and mixed doubles are included.

Long story short, nowadays, the highest organization for the sport of badminton is Badminton World Federation [2]. BWF has expanded to 176 member nations around the world. In 1992, badminton was introduced to the Summer Olympics as a full medal sport [3]. Recently badminton has become the second most popular sport worldwide in participation with more than 200 million adherents [4] [1].

In terms of the features of badminton competition, researchers and scholars described as: the shuttlecock has an nonconforming path and the players perform particular movements such as lunging, jumping and powerful hits using a precise pattern of movement [5]. During a match, player is required to consume up to $90 \%$ of his or her maximal heart rate. The intermittent actions during a badminton match are required the works from both the aerobic and anaerobic systems: about $30 \%$ on the anaerobic system, and $60-70 \%$ on the aerobic system with respect to the lactic anaerobic metabolism; moreover, badminton sport can best fit and beneficial players' eye-hand, eye-feet cooperation, and agility finesses in a short time [5].

The simplicity of badminton makes it an attractive lifetime recreational activity. The speed and the power of the shots are the factors that determine they are in a recreation level or a professional level. To reach professional level for everyone that is an incredible challenge, because badminton game requires extremely well developed agility and hand-eye coordination. Its winning strategies demand deft touch skills, such as: make a power smash to the placement you want; make a drop shot into a precise area of the opposite court; in an elite level, players can strike the shuttle in speeds of 140 to $160 \mathrm{mph}$ [5]. Additionally, due to the height of the net and the dimensions of the court, taller or bigger / stronger athletes should be possess advantage in the sport of badminton, however, the Olympics badminton gold medal winners and recent champions at world badminton championships have been dominated by the players came from China, Indonesia, Malaysia, and Korean, because of their genetic traits, such as: slighter body and dexterity which are more suitable to the game of badminton [1]. 
Furthermore, badminton scientific literatures mainly focus on the sports dimension and all that affects the outcome of its competition, such as: techniques or tactics, movement patterns of players [6]; game characteristics, anthropometry, physiology, visual fitness and biomechanics [5]; call for the expansion of badminton as a collegiate sport [7] (Feng, 2014). Research studies reflected players' participation motivations in badminton, however, are extremely limited. Generally speaking, the purposes and reasons of taking part in youth sports practices and competitions are: 'enjoyment', 'physical health', 'having fun', 'foster self-esteem', 'friendship', 'passion or love the game', and 'peer acceptance', whereas the first three reasons are similar to those participate in the dominant recreational activities of Western societies [8] [9] [10] [11]. Additionally, researchers indicted that motivation supports a successful sport performance; representing one of the most important psychological skills in the game he/she is playing [12]. Since that being the case, we are concerning: Are youth badminton players motivated to continuely engage in their practices and competitions as what have been described above?

\subsection{Purpose and Hypotheses}

According to the above background introduction, although some of the reasons (as listed above) have known in general, little is known about what kinds of factors or reasons that actually motivated various types of youth players who have continually engaged in badminton practices and competitions. The purpose of this study, therefore, was to explore what factors or reasons that truly motivated the youth players in two different education and skill levels who have engaged in youth badminton practices and competitions for years in Jiangsu province, China. The following specific hypotheses guided the current study: (a) No significant differences would be found on the motivation factors (MFs) between the 'Gender' of the participants; (b) no significant differences would be found on the MFs between 'Education Levels' (Middle-school vs. High-school) of the participants; (c) no significant differences would be found on the MFs between 'Athletes-Types' (Sport-SchoolAthlete vs. Traditional-Badminton-School-Varsity-Athlete) who took part in badminton practices and competitions.

Moreover, eleven relate elements on their 'Free Times', 'Activities-Engagement', 'Practicing Frequency', 'Training Condition' and 'Competition Frequency' of the youth badminton players were also in the plans of this study. The findings from this research would reveal and add a new set of data and first-hand information into the youth athletes study literatures, especially concerning to youth badminton athletes' motivations and relative elements in their badminton practices and competition.

\subsection{Theoretical Framework}

The present study was guided by the theory of intrinsic and extrinsic motivation. Ryan and Deci (2000) indicated, a comprehensive theoretical framework called the 'self-determination theory' (SDT) emphasizing that: humans are motivated by three basic psychological needs: competence, relatedness, and autonomy [13]. The competence needs in SDT model is called effectiveness motivation; the relatedness needs refers to people's need to belong and to feel accepted by others; and the autonomy need, however, refers to people's need to feel self-determined, it is the source of their own action [13].

Similarly, Harter (1981) and Pintrich and Schunk (2002) described that organismic needs energize intrinsic and extrinsic motivations, but believe this concept is too general to explain engagement in specific behaviors (e.g., engage in sport competitions) [14] [15]. Researchers, therefore, developed a few models that described how motivation triggered by needs manifests in intrinsic and extrinsic motivation in specific fields and activities. These models also explained how factors in a specific environment might shape and affect the types of motivation that people manifest in different activities [15].

Specifically, Breese (1998) pointed out, athletics initial motivation should be defined as intrinsic motivation (participating in sport for enjoyment) or extrinsic motivation (participating in sport to gain rewards) [16]. Breese continued, athletics initial motivation usually predicts athletes' attendance and adherence to a particular sport [16]. Such as in the present study, a youth badminton player who is intrinsically motivated would be those who go to play or practice his or her skills every other day for fun; whereas a youth badminton player who is extrinsically motivated would be those who goes to play or practice his or her badminton skills to become a better player at the competition so that he/she could win a medal at a competition. It is interesting to know that intrinsic and extrinsic motivation have different effects on an athlete/player, including whether or not he/she continue on the sport he/she had choose.

Furthermore, Researchers (1997) explained that individuals who were mainly motivated by competence (engaging in exercise to expand skills) and enjoyment (desire to have fun) could be primarily defined as being motivated intrinsically [17]. In contrast, extrinsically motivated individuals are those behaviors performed in intrinsic motivation aim at to obtain rewards or consequences that are separate from the behavior itself [17]. Breese (1998) also illustrated that when athletes/players begin participation in a particular sport, they are motivated not only by intrinsic factors but also extrinsic factors [16]. Some particular sports, however, may 
be more relying on intrinsic motivation than extrinsic motivation [17]. The reasons are: different types of sports need different types of motivation [17]. In the present study, we were trying to find out those evidences or the factors that have actually motivated the participants who have engaged in and continuely engaging in the sport of badminton.

\subsection{The Sampling}

\section{Methodology}

Sampling for participants in the present study were selected from the Jiangsu Province Youth Badminton Championships \& Tenth Secondary School Badminton Tournament (2014, Nanjing, China) [18]. According to Jiangsu.net (2017), Jiangsu province possesses the following unique features: a). Jiangsu is one of the most developed areas in China in economy, technology and culture; its industries total output is one of the largest in the nation; b). Jiangsu is a center of education and science in China; possessing the highest density of academic institutions and universities, colleges, and research institutes; c). Jiangsu has nurtured nearly 40 international badminton superstars; including World Badminton Championship, Olympics Badminton competition, and Thomas Cup Champions since 1980s; such as, Yang Yang, Zhao Jianhua, Shi YuQi, Tang Jinhua, and Jiang Yanjiao [19] [20]. This is why we intentionally selected Jiangsu province as the sample.

\subsection{Data Collection}

The questionnaires were distributed to the participants during the Jiangsu Province Youth Badminton Championships \& Tenth Middle School Badminton Tournament. The participants were given 'Directions' on how to respond to questions and the items on the questionnaire; their rights to participate or not to participate were informed and the 'confidentiality' of the survey was also instructed. An envelope to prevent participant's coach from viewing the returned questionnaires was provided; the participants signed the Informed Consent by this moment.

The coaches were informed that: After the study accomplishing she/he would be provided the overall outcomes of the study. As a result, 87 youth players correctly completed the questionnaire and returned to the researchers (Note: questionnaires distributed were 110, 87 returned, return rate $=79 \%$ ).

\subsection{The Instrumentation}

The Adopted Questionnaire of Badminton Player's Motivation ${ }^{- \text {C.V. }}$ (AQBPM ${ }^{\text {-C.V. }}$ ) [21] was employed for data collection. The reasons for using this questionnaire were: a) There is an existing questionnaire with similar purposes; b) to develop a new questionnaire, more funds and times would need; c) there were specialists are available for revising key words from the exist questionnaire to specify uses for youth badminton players; $d$ ) research assistants or youth badminton coaches were available for questionnaire distribution and collection.

\subsubsection{Reliability and Validity of the Instrument}

Child (1990) indicated that in order to explore the possible underlying factor of the structure of a set of measured variables without imposing any preconceived structure on the outcome, the exploratory factor analysis (EFA) is the best solution [22]. Therefore, the EFA was executed. The results showed: the analysis extracted 6 factors with perfect correspondence to the 18 items with eigenvalues for the reasons or factors ranging from 2.48 to 8.25 and structure coefficients from .75 to .91 and the majority of the fitted residuals reached the pre setup significant difference $(P<.05)$ level.

Additionally, the validation process was through a pilot study, reviewing to the content or items. These processes confirmed the following concerns: a) the readability and writing skills of the youth participants (13 17 years old); b) whether or not those young participants can truly understand and complete the questionnaire correctly; c) it may result in re-wording on some questions or statements to improve the understanding for those youth players; d) it may result in cutting or adding numbers of the questions or statements in the questionnaire, and e) whether or not the questions or statements have asked all the possible motivation reasons or factors for the players participation in badminton practices and competition.

As a result, the AQBPM ${ }^{\text {C.V. }}$ [21] contained three parts: Part I asked 'General Information', containing seven questions that cover participant's general information. Part II asked, "What reasons/factors motivate you to take part in badminton practices and competitions continually" with 18 motivation factors (MFs) provided. In each MF the participant responds in 5-points Likert type scale (5-points represents "Strongly agree ", 4-points represents "Agree", 3-points represents "Somewhat-agree", 2-points represents "Little-agree", and 1-point represents "Disagree"). Part III asked 11 relate questions or elements that concern the youth players' 'Free Times', 'Activities-Engagement', 'Practicing Frequency', 'Training Condition' and 'Competition Frequency'. To be clearer, the 11 relate questions or elements in the part III are belong to qualitative data, hence, the frequency and percentage were used for dealing with these data.

In summarize, the Part II in the questionnaire, contains nine intrinsic motivation factors (i.e., items 1, 2, $6,7,9,13,14,15, \& 18$ ); and nine extrinsic motivation factors (i.e., items $3,4,5,8,10,11,12,16, \& 17$ ). In the 
other words, it included the three basic psychological needs (i.e., competence, relatedness, and autonomy) described by the researchers [14]. The part III contains 11 relate questions or elements about the youth players' training and competition status, which is qualitative data. All questions and items in AQBPM $^{\text {-C.V. }}[21]$ can be found in Table 2 and Table 5.

\subsection{Research Design and Data Analyze}

The main goal for data analyses in current study was to look at the effects of three independent variables on 18 dependent variables. That is: 'Gender' (Male vs. Female) x 'School-Levels' (Middle-School vs. High-School) x 'Athletes-Types' [Sport-School-Athlete (SSA) vs. Traditional-Badminton-School-VarsityAthlete (TBSVA)] at the same time. Therefore, a $2 \times 2 \times 2$ MANOVA, and a follow up MANOVA test after significant differences findings were operated. The descriptive statistics reflected the general status of how the participants were motivated participating in badminton practices and competition; the $2 \times 2 \times 2$ MANOVA examined whether or not there are significant differences exist among the three independent variables and the 18 dependent variables. The follow up MANOVA test reflected what differences exactly exist among the dependent variables. The statistical program used for the data analyses was IBM Statistical Package for the Social Sciences (SPSS) Version 22 [23].

\subsection{Participants' General Information}

\section{Results}

The following section presents the findings from the present study. It is structured to address the reasons / factors that the participants engaged in the sport of Badminton. In total of the 110 questionnaires distributed, 87 were returned and completed correctly; this represents a response rate of $79 \%$. Data in Table 1 reflected "General Information of the participants". For example, the participants self-reported that they officially take part in Badminton practicing and competition were: In male side, 52 or 100\% of them reported them have four or more years regularly take part in badminton practices and competition experience; wherein 20 or $38.5 \%$ claim them were SSA, 32 or $61.5 \%$ claim them were TBSVA. In female side, 35 or $100 \%$ of them reported them have four or more years regularly take part in badminton practices and competition experience; wherein 12 or $34.28 \%$ claim them were Sport School Athletes (SSA), and 23 or $65.71 \%$ claim them were TBSVA. It is worth to illustrate that: the SSA represent the highest skill and competitive capability in nonprofessional level in Chinese competitive sport system; athletes in sport school practice at least five half day per week, including a morning exercise and an afternoon practice. While the TBSVA represents the level of skill and competitive capability slightly below those athletes in sport school. The youth athletes in traditional badminton school have 4 to 5 after school practices per week with practice time no more than two hours. Much of the detail can be found in Table 1:

TABLE 1 General Information of the Youth Badminton Players $(N=87$; Males $=52$, Females $=35)$

$\frac{\text { \# Questions }}{\text { For males only: }\left(n_{1}=52\right)}$

1) What is your gender?

2) What are your Height and weight?

3) What is your age rank?

4) How long have you in gage in official badminton training?

5) What type is your badminton school?

6) What is your current school level?

7) Where do you live during you have badminton training/practicing?

For females only: $\left(n_{2}=35\right)$

1) What is your gender?

2) What are your Height and weight?

3) What is your age rank?

4) How long have you in gage in official badminton training?

5) What type is your badminton school?

6) What is your current school level?
Answers / Frequency / Percentage

Male $52 / 59.77 \%$

Height $=165-196$ CM, Weight $=45-98$ Kilometer.

$15 \pm 2 /$ 13-17 Years.

4 or more years $=52 / 100 \%$

Sport-School-Athletes $($ SSA $)=20 / 38.5 \%$

TBSVA $=32 / 61.5 \%$

Middle school (MS) $=28.60 / 55 \%$

High school $($ HS $)=23.40 / 45 \%$

Home $=38 / 73.07 \%$

Dome 14 / 26.92\%

Female $35 / 40.23 \%$

Height $=160-178 \mathrm{CM}$, Weight $=42-70$ Kilometer

$15 \pm 2 / 13-17$ Years.

4 or more years $=35 / 100 \%$

Sport-School-Athletes $(\mathrm{SSA})=12 / 34.28 \%$

TBSVA $* 23 / 65.71 \%$

Middle School (MS) $=20 / 57.14 \%$ 
7) Where do you live during you have badminton training/practicing?
High School $(\mathrm{HS})=15 / 42.86 \%$

Home $=29 / 82.86 \%$

Dome $6 / 17.14 \%$

Note. ${ }^{*}$ TBSVA $=$ Traditional Badminton School Varsity Athletes

Data in Table 2 reflected the "Factors that motivated the youth badminton players to initially take part in, keep practices and continuing engage in badminton competition". As can be seen, the top five factors were MF3 'For healthier', MF1 'Technical content \& unique value', MF16 'Develop unique skills', MF11 'For my own-biography' and MF8 'For health status' $(M=4.540$ to $M=3.988)$, these five factors possessed the highest impact power on these youth badminton player's motivation; the bottom five factors were MF17 'Become a coach', MF18 'Satisfy the will of family', MF9 'Become professional player', MF13 'Get recognition', and MF4 'To meet friends' $(M=2.126$ to $M=3.241)$ these five factors possessed less or lower impact power on these youth badminton player's motivation. While the other eight factors' mean score were from $M=3.276$ to $M$ $=3.908$, which means these factors had medium impact power on these youth badminton player's motivation. Means and standard deviations on factors / reasons that motivated the youth players took-part in Badminton practices and competitions were presented in Table 2:

TABLE 2 Factors / Reasons that Motivated the Youth Badminton Players Means Score and Standard Deviations $(N=87$, Males $=52$, Females $=35)$

\begin{tabular}{llr}
\hline Motivation Factors (MF) & $M \pm S D$ & Sum \\
\hline MF1. Because Bademinton with high technical content and unique value. & $4.506 \pm .729$ & 392.00 \\
MF2. For the fun and get rid of boredom. & $3.908 \pm 1.085$ & 340.00 \\
MF3. For getting healthier & $4.540 \pm .860$ & 395.00 \\
MF4. In order to meet friends. & $3.241 \pm 1.422$ & 281.97 \\
MF5. In order to make new friends. & $3.586 \pm 1.234$ & 311.98 \\
MF6. In order to contest winners. & $3.494 \pm 1.328$ & 303.98 \\
MF7. In order to shape the body. & $3.299 \pm 1.398$ & 287.01 \\
MF8. In order to improve health status. & $3.988 \pm 1.325$ & 346.95 \\
MF9. For the near future may become a Badminton professional player. & $2.459 \pm 1.523$ & 213.93 \\
MF10. In order to establish self-esteem. & $3.483 \pm 1.256$ & 303.02 \\
MF11. In order to improve my own-biography. & $4.103 \pm 1.203$ & 356.96 \\
MF12. In order to establish prestige among my friends. & $3.276 \pm 1.326$ & 285.01 \\
MF13. In order to get the recognition from my teacher / coach. & $3.207 \pm 1.231$ & 279.01 \\
MF14. In order to reduce pressure from academic learning. & $3.391 \pm 1.242$ & 295.02 \\
MF15. In order to reduce troubles from school works. & $3.494 \pm 1.218$ & 303.98 \\
MF16. In order to develop one unique skills. & $4.299 \pm .877$ & 374.01 \\
MF17. Want to become a Badminton coach in the future. & $2.126 \pm 1.283$ & 184.96 \\
MF18. In order to satisfy the will of family. & $2.333 \pm 1.074$ & 202.97
\end{tabular}

Note. 1) The motivation factor (MF) 1, 2, 6, 7, 9, 13, 14, 15, and 18 are 'Intrinsic motivation factors'; and the MF 3, 4, 5, 8, 10, 11, 12, 16, and 17 are 'Extrinsic motivation factors'. 2) MF3, MF1, MF16, MF11, \& MF8 scored on the top; the MF17, MF18, MF9, MF13, \& MF14 scored on the bottom.

The results of the $2 \times 2 \times 2$ MANOVA for comparing the motivations factors / reasons from different types of players' were presented in Table 3:

Table 3: 2 (Gender) x 2 (School-Levels) x 2 (Athletes-Types) MANOVA Comparing Youth Badminton Players' Motivations Factors ${ }^{\mathrm{a}}(N=87$; Male $=52$, Female $=35)$ from different School-levels and AthletesTypes.

\begin{tabular}{lccccc} 
Source & $\begin{array}{c}\text { Wilks' } \\
\text { Lambda }\end{array}$ & $F$ & $\begin{array}{c}\text { Hypo } \\
d f\end{array}$ & $\begin{array}{c}\text { Error } \\
d f\end{array}$ & $P$ \\
\hline Gender & .675 & $1.661^{\mathrm{b}}$ & 18.000 & 62.000 & .072 \\
School-Levels & .442 & $4.357^{\mathrm{b}}$ & 18.000 & 62.000 & .000 \\
Athletes-Types & .267 & $9.466^{\mathrm{b}}$ & 18.000 & 62.000 & .000 \\
\hline
\end{tabular}


Note. ${ }^{a}$ Design: Intercept + Gender + School-Levels + Athletes-Types; ${ }^{b}$ Exact statistic.

The results of the 2 (Gender) x 2 (School-Levels) x 2 (Athletes-Type) MANOVA in Table 3 showed that: no significant difference in the 'Gender' factor $(p>.05), \Lambda=.675, F=1.661$; however, significant differences effects were found in 'School-Levels' factor $(p<.000), \Lambda=.442, F=4.357$, and in 'Athletes-Types' factor $(p<.000), \Lambda=.267, F=9.466$.

According to the research design, after significant differences effects were found, a following up $2 \times 2$ ['School-Levels' (Middle-school vs. High-school] x ['Athletes-Types' (SSA vs. TBSVA)] MANOVA was further conducted. These post hoc tests determined where and what factors / reasons truly motivated the players continuely practicing and competing Badminton; the findings were present in Table 4:

Table 4: Descriptive Statistics of Players' Motivations for Practicing and Competing Badminton from SchoolLevels (High-School or Middle-School) and Athletes-Types (SSA vs. TBSVA)

\begin{tabular}{|c|c|c|c|c|}
\hline \multirow{2}{*}{$\begin{array}{l}\text { Motivations } \\
\text { Factors (MF) }\end{array}$} & \multicolumn{2}{|c|}{ School-Levels - Mean (SD) } & \multicolumn{2}{|c|}{ Athletes-Types- Mean (SD) } \\
\hline & Middle-School (52) & High-School (35) & SSA (30) & TBSVA (57) \\
\hline MF 1 & $4.442 \quad(.802)$ & $4.600 \quad(.604)$ & $4.600 \quad(.855)$ & $4.456 \quad(.656)$ \\
\hline MF 2 & $4.134(.792)^{*}$ & $3.571(1.356)$ & $4.167 \quad(.746)$ & $3.772(1.210)$ \\
\hline MF 3 & $4.538(.938)$ & $4.543(.741)$ & $4.600 \quad(.894)$ & $4.509 \quad(.847)$ \\
\hline MF 4 & $3.423(1.413)^{*}$ & $2.971(1.599)$ & $3.533(1.252)^{*}$ & $3.087(1.491)$ \\
\hline MF 5 & $3.731(1.156)$ & $3.371(1.130)$ & $3.933(1.330)^{*}$ & $3.403(1.222)$ \\
\hline MF 6 & $3.403(1.317)^{*}$ & $2.257(.950)$ & $4.233(1.006)^{*}$ & $3.105(1.318)$ \\
\hline MF 7 & $3.403(1.317)$ & $3.143(1.517)$ & $3.566(1.156)$ & $3.158(1.485)$ \\
\hline MF 8 & $3.865(1.358)$ & $4.171(1,271)$ & $4.233(1.072)^{*}$ & $3.859(1.432)$ \\
\hline MF 9 & $3.057(1.487)^{*}$ & $1.571(1.092)$ & $4.266(.521)^{* *}$ & $1.501 \quad(.868)$ \\
\hline MF 10 & $3.653(1.266)$ & $3.228(1.214)$ & $3.800(1.214)$ & $3.315(1.255)$ \\
\hline MF 11 & $3.981(1.305)$ & $4.285(.825)$ & $4.166(.791)$ & $4.070(1.131)$ \\
\hline MF 12 & $3.519(1.305)^{*}$ & $2.914(1.291)$ & $3.633(1.233)^{*}$ & $3.087(1.326)$ \\
\hline MF 13 & $3.423(1.193)^{*}$ & $2.885(1.231)$ & $3.433(1.165)$ & 3.087 (1.257) \\
\hline MF 14 & $3.519(1.111)$ & $3.200(1.828)$ & $3.300(1.342)$ & 3.438 (1.195) \\
\hline MF 15 & $3.750(1.045)^{*}$ & $3.114(1.367)$ & $3.767(1.165)$ & $3.351(1.231)$ \\
\hline MF 16 & $4.384 \quad(.899)$ & $4.171(.857)$ & $4.600 \quad(.674)$ & $4.140 \quad(.934)$ \\
\hline MF 17 & $2.576(1.318)^{*}$ & $1.457(.885)$ & $3.466(1.041)^{* *}$ & $1.421 \quad(.705)$ \\
\hline MF 18 & $2.269(1.104)$ & $2.428(1.037)$ & $2.400(1.191)$ & $2.300(1.017)$ \\
\hline
\end{tabular}

Note. This is a follow up test to determine what and where really have significant differences. *Significant at $p<.05$. Level. $* *=$ Significant at $p<.01$. Level. There are 15 comparisons showed significant differences. MF1 to MF18 Represent 18 different motivation factors - see Table 2 for details.

The findings from part III of the questionnaire, which was 11 elements, related to the participants' 'Free Times', 'Activities-Engagement', 'Practicing Frequency', 'Training Condition' and 'Competition Frequency' are sumarized and presented in Table 5:

Table 5: Relate Elements on 'Free Times', 'Activities-Engagement', 'Practicing Frequency', 'Training Condition' and 'Competition Frequency' of the Youth Badminton Players $(N=87$; Males $=52$, Females $=35)$

No. Questions

Answers / Frequency / percentage

1) How many free time do you have from Monday to Friday?
a) No free time at all $-0 / 0 \%$
b) 1 hour -- $11 / 12.64 \%$
c) $2-4$ hours $35 / 40.23 \%$
d) more than 4 hours $41 / 47.13 \%$

2) How many free times do you have during weekend?
a) 1-2 hour $-0 / 0 \%$
b) 3- 4 hours 37 / $42.53 \%$
c) 5-6 hours $41 / 47.13 \%$
d) 7 hours and more $8 / 9.19 \%$

3) What kind of activities do you do in your free time, besides badminton training?

(There A - H choices; choose as many as it fit your situation) SEEp
a) Reading books/magazines $13 / 14.94 \%$
b) Watching TV 33 / 37.93\% 

c) Play computer $24 / 27.58 \%$
d) Listening to music $16 / 18.890 \%$
e) Social meetings $5 / 5.75 \%$
f) Other physical activity $37 / 42.53 \%$ is

4) Do you undertake physical activity willingly in your free time (included play badminton and other kinds of activity)?
a) Yes, $81 / 93.10 \%$
b) No, 6 / 6.89\%

5) Accept badminton, what physical activity do you involve often?
a) Swimming $10 / 11.49 \%$
b) Jogging $16 / 18.39 \%$
d) Fitness $11 / 12.64 \%$
e) Gymnastics $0 / 0 \%$
c) Body building $23 / 26.43 \%$
g) Ride bike $23 / 26.43 \%$
h) Walking $11 / 12.64 \%$
f) Team sports $23 / 26.43 \%$
h) Martial arts $10 / 11.49 \%$

6) What is your frequency to engage in sports/physical activities? (Including play Badminton.
a) Every day $28 / 32.18 \%$
b) Four times per week $31 / 35.63 \%$
c) Three times per week $18 / 20.68 \%$
d) Two times per week $9 / 10.34 \%$

7) Can you access to Badminton or Sports-facilities easily or difficultly?
a) Very easily -- $45 / 51.72$
b) Easily -- $38 / 43.67 \%$
c) It's depend -- $4 / 4.59 \%$
d) Difficultly -- $0 / 0 \%$
e) Very difficulty -- $0 / 0 \%$

8) Does your financial situation allow you to participate in Badminton practice and competition?
a) Yes -- $58 / 66.67 \%$
b) No $-29 / 33.33 \%$ (-varous reasons)

9) How often do you attend Badminton competition during a semester?
a) Never -- $0(0 \%)$
b) Once per semester - 34 / 39.08\%
c) 3 to more times per semester -- $10 / 11.49 \%$
d) Others -- $0 / 0 \%$

10) Do you attend Badminton competition in winter / summer vacations?
a) Yes, always -- $49 / 56.32 \%$
b) Usually -- $38 / 43.68 \%$
c) Once in winter or summer -- $0 / 0 \%$
d) $\mathrm{No}--0 / 0 \%$

11) Who pay for the travel and registration fee for your Badminton competition? (-can choose multiples answers)
a) My parents -- $15 / 17.24 \%$
c) My team / club 34 39.08\%
b) My school -- $38 / 43.68 \%$
d) Myself -- $0 / 0 \%$

Table 5 reflected the findings on the 11 relate elements that were 'Free Times', 'ActivitiesEngagement', 'Practicing Frequency', 'Training Condition' and 'Competition Frequency' of the participants. Although these elements are not in the motivation factors list but they have essential relationship with participants' motivation; because that was really matter to whether or not the youth badminton players want to take part in their practicing and competitions continuely.

Significantly, the participants self-reported that: a) from Monday to Friday, $40.2 \%$ had 2-3 hours, and $47.1 \%$ had more than 4 hours; b) during weekend, $42.5 \%$ had 3-4 hours, and $47.1 \%$ had 5-6 hours; c) In their 'free time', $37.9 \%$ watched TV, and $42.5 \%$ played other physical activity; d) $93.1 \%$ of them were willingly attended physical activities, only $6.9 \%$ of them told they were not willingly; e) $32.2 \%$ attended physical activities (including badminton) every day, and $35.6 \%$ attended physical activities (including badminton) four times per week; f) $51.7 \%$ were very easily access to the facilities, and $43.6 \%$ of them claimed they could easily access the facilities; g) $66.6 \%$ said their financial situation allowed them to participate in Badminton practice and competition, but $33.3 \%$ of them reported their financial situation was not allow them to participate with multiple reasons; h) $50.5 \%$ of the participants reported them at least attend Badminton competition one time per semester; i) $56.3 \%$ of them reported them always attend Badminton competition in winter or summer vacations, and $43.7 \%$ of them reported they usually did so as well; $j$ ) the respond rate for "Who pay for the travel and registration fee for your Badminton competition?" were: $17.2 \%$ by my parents, $43.7 \%$ by my school, and $39.1 \%$ by my team or club.

\section{Discussion}

The present study was designed to explore the current status of youth badminton players' participation motivations in Jiangsu, China; and to examine whether differences would exist on the motivation factors / reasons among the participants' 'Gender', 'School-Levels' and 'Athletes-Type'. First, as displayed in the results section (Note. the following arrangement was in accordance with the scores to determine the order; see Table 2 for details), among the five top highest scored factors - that were MF3, MF1, MF16, MF11 and MF8, these factors possessed the highest impact power on this sample's motivation. Remarkably, among these factors, besides MF1, other four MFs are belonging to 'Extrinsic factors'. Second, among the eight second higher score factors, MF2, MF6, MF7, MF14 and MF15 are belonging to 'Intrinsic factors', while MF5, MF10, MF 12 are belong to 'Extrinsic factors'. Third, the lower five score factors were MF4, MF9, MF13, MF17, and MF18; in which MF9, MF18, and MF13 are belonging to 'Intrinsic factors'; but MF4 and MF17 belong to 'Extrinsic 
factors' (see Table 2); therefore, we can generally conclude: 1) the current study exposed that for motivating youth badminton players, the 'Intrinsic factors' possess higher impact power than those of 'Extrinsic factors'; 2) the nine 'Intrinsic factors' in the $\mathrm{AQBPM}^{-\mathrm{cv}}$ [21] were the core motivation factors for youth badminton players; 3 ) there are some factors or reasons possessed higher impact power than the other factors, and there are some factors or reasons owned less impact power than the others factors as well. Coaches, instructors or administers need to apply these findings accordingly. The motivation features of this sample are summarized as Fig 1.

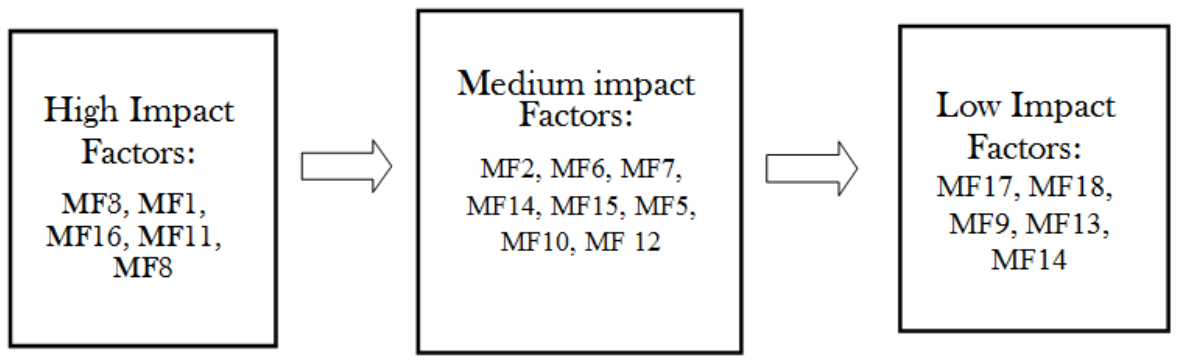

Figure 1. Three Layers of Youth Badminton Players' Motivation Factors

Note. 1) Intrinsic factors $=$ MF1, 2, 6, 7, 9, 13, 14, 15, \& 18; 2) Extrinsic factors $=$ MF3, 4, 5, 8, 10, 11, 12, 16, \& 17; and 3) These18 factors reflected the 'Competence Needs', the 'Relatedness Needs' and the 'Autonomy Need' in the 'Self-Determination Theory' model interpreted by Ryan and Deci (2000) [13].

General speaking, there were 15 MFs displayed at significant different $(P<.05)$ level among the total 36 comparisons, specifically in 'School-Levels' revealed $8 \mathrm{MFs}$; and in 'Athletes-Types' exposed $7 \mathrm{MFs}$. We would like to have more in deeper discussion below. First, regarding the 'School-Levels', among the 18 factors, 8 of them were found at significant differences level. Where the youth players at 'Middle-School' scored remarkable higher than the youth players from 'High-School'. Specifically that are: MF2 - 'having fun'; 'MF 4 - 'meet friends'; MF 6 -'to contest winners'; MF9 - 'to become a professional player'; 'F12 - 'to establish prestige'; MF13, 'to get the recognition'; MF15 - 'to reduce troubles'; and F17 - 'become a coach'. Why those happen? What would be the reasons behind of those? We believe this is a common facts that at middle school level, youth badminton players are keen on making new friends, establish their self-esteem and prestige, contest winners, and becoming a professional athlete or coach than those youth players at high school level; therefore these 8 MFs possessed much higher impact power on their participation motivation. Second, to the youth players from higher school level, when they facing those motivation questions / factors (such as: meet friends, contest winners, get the recognition, establish prestige, and become a professional player) their responds showed much less excitement than those youth players at middle school level; because they have tasted or have had those experiences during them were at that level. Furthermore, naturally during the last two years in high school, because of they would face the enrolment examination in order to get a chance to go to a college or an university in one or less than two years, that have become their top priority; therefore the results of this survey were reasonable and logic.

On the other hand, concerning the motivation factors comparisons in the 'Athletes-Types', the interesting and unique aspects are: 1) The players in the sport-school were significantly more appreciate the motivation factors of MF4 - 'meet friends'; MF5 - 'make new friends'; MF6 - 'to contest winners'; MF8 - 'to improve health status'; MF9 - 'to become a professional player'; MF12 - 'to establish prestige'; and MF17'become a coach'. Again, what were the reasons of these?

As introduced before, athletes in sport schools represent the highest skill and competitive capability in non-professional level in Chinese competitive sport system; they practice five half day per week, and attend 2-3 major youth competitions every semester (Spring and Autumn), plus every four years there is a National Middle School Games [24] and National Collegiate Games [25] Those promising teenagers are eagerly hope they will able to be sent to sports schools to receive specialized training, so that they can make their sport-star dream come true; therefore, the expectations on their winnings from all aspects are pretty high that are their important external motivation resources. On the other hand, although the youth athletes at the traditional sports school have less times for practicing and competing and lower percentage rate to become a sport-star, but they are still in the category of 'promising teenagers' and have possibility to be successful athletes in their selected sport as well. Likewise, many youth athletes at traditional sports school have targeted or motivated through playing and competing in National Collegiate Games - that was called different 'sport-star dream'; but really reflected where their motivations come from, whereas this kinds of motivations are similar to the 'Intrinsic motivation'.

As we pointed out at the beginning, "research studies involved motivations of taking part in badminton are extremely limited", but there was one investigation that conducted at college / university level: Khan, Haider and Ahmed (2011) investigated 30 (Male $=15$, Female $=15$ ) collegiate badminton players' participation 
motivations using the Sports Achievement Motivation Test questionnaire during an inter-university badminton tournament [26]. The data analysis method was t-test. One of their major finding was: there was no significant difference between the male and female collegiate badminton players on achievement / participation motivations. This is consistent with one of the current findings - that is, no significant differences between the males and females youth badminton players.

Then, further discussions could be: Besides some similarities between the current findings and findings from other previous studies; some differences exist as well. For examples, the following are similarities: (a) regardless age and school levels, no significant differences in players' participation motivations between their gender. Using those previous studies findings for the sport of Tennis (Note. since lack of resources in youth badminton participation motivations, we would like to use the research findings from youth Tennis). (b) Miguel and Machar (2007) in their review of literature "Motivation in Tennis" summarized that [12] 1) 'enjoyment', 'fun', 'passion' and 'love for the game' were rated as top important motivation factors for youth tennis players' success. 2) 'Improving performance', 'keeping physically fit' and 'socializing' were rated as their basic reasons for youth tennis players' involvement in the sport. 3) 'Feeling important and popular', and 'earning rewards' were ranked as less important motivations. 4) School, club, or team atmosphere and having a good relationship with the coach was also an influenced factor of players' participation [12].

Interestingly, although our study and their studies were conducted in two different sports but findings from the two sports were more similar than differences. Whereas, in general, their top important and basic reasons for the youth players took-part in sport practices and competitions were very similar when contrast to the top 7 motivation factor /reasons of the current study (See table 1 for details). In particular, with regard to the differences, in the factors 'feeling important and popular', 'earning rewards' 'team atmosphere' and 'good relationship with coach'; although there were some similar with the athletes from Sport-schools athletes, but there were a lots of differences to the athletes from Traditional Badminton schools athletes (As showed in Table 4); wherein the athletes from Sport-schools ranked 'become a badminton coach', 'become a professional player', 'to contest winners', 'to improve health status', and 'to establish prestige' as their top priority. That was huge different from the previous studies.

\section{Limitations}

There were several limitations in the present study: first, the size of sampling in this study was relatively small; second, the data collection scope only covered one youth badminton tournament in Jiangsu province; third, badminton coaches might have some kinds impacts on their athletes' participation motivations, but that had not included in the objects of the current study; and the last, the participants in the current study were selected on purpose. Future studies can be improved on the above limitations by including the coaches from those participants' teams (e.g., creating some open-ended questions for coaches to answer); extend data collection to more tournaments; and select participants more thoroughly.

\section{Conclusion}

With regard to the three specific hypotheses that guided the present study, the findings revealed that one is not true, and two are true wherein: (1) No significant differences exist on the motivation factors between the gender of the youth athletes/players; (2) Significant differences do exist on the motivation factors among the 'school-levels' of the 'types of athlete/players', with 8 out of 18 comparisons showed significant differences; that were middle-school athletes/players had higher motivation scores than those of the high-school athletes/players; (3) Significant differences do exist on the motivation factors among the 'Athlete-Types' of the athlete/players, with 7 out of 18 comparisons showed significant differences; that were 'SSA' had higher motivation scores than those of the 'TBSVA' (as showed in Table 4).

Regarding with the 11 relate elements of the participants, that are: 'Free Times', 'ActivitiesEngagement', 'Practicing Frequency', 'Training Condition' and 'Competition Frequency'. The significant findings are summarized as: a) the participants had enough time for their practices during weekdays and weekend; b) the youth badminton player were willingly attended physical activities or badminton practices; c) the frequencies of their participation were 4-6 times per week; d) the participants can easily to access the badminton facilities whenever they schedule practices; e) 2/3 of the participants had no financial problem to participate in Badminton practice and competition, but $1 / 3$ of them had financial problem to do so; f) more than $4 / 5$ participants reported it was their school or teams paid for the cost of their travel and competitions, only less that $1 / 5$ participants claimed their travel and competitions cost were paid by their parents.

In conclusion, the findings of this investigation showed: Gender is not the determination aspect; 'School-Levels' and 'Athlete-Types' are. The youth badminton athletes at the 'Middle-School' possess higher motivation than those from the 'High-School'. Athletes/players from 'Sport-school' possess higher motivation than those athletes/players from 'Traditional Badminton-School'. Furthermore, with regard to the participate motivations; the 'Intrinsic factors' possess higher influence power than those of the 'Extrinsic factors'. 
Specifically, the following motivation factors (MFs) such as: MF3 'For healthier', MF1 'Technical content \& unique value', MF16 'Develop unique skills', MF11 'For my own-biography', MF8 'For health status', and MF2 'For the fun' possess remarkable impact power on youth badminton athletes/players' participation motivations; which means: some MFs had higher influence power, some MFs had less influence power. Youth sport educators need to base on deeper analysis on their athletes/players and apply these findings or research results correspondingly.

\section{Recommendations}

The present study explored the youth badminton athletes/players' participation motivations and related elements from a remarkable international badminton champion birthplace - Jiangsu province, China. Badminton's 'technical content and unique value', 'unique skills', 'participants' biography', 'health status' and 'enjoyment' have been found as the main reasons for the participants involved in this sport. While to become a professional athlete or coach, and satisfy family's wish represented less important motives, whereas school or team atmosphere and having a good relationship with coaches also influenced athletes/players' participation motivations. Although the values of youth athletes' participation motivations have been recognized by many youth sport researchers [12] [10] [17], however, future studies need to extent the size and locations of sample, examine those effective strategies to better cultivate participation motivations among at various youth athlete that are highly expected.

\section{Acknowledgements}

For the financing supports provided by the Education Research Institution of Jiangsu Province, Nanjing, China, the researchers of this study want to express our deepest appreciation and many thanks! To the participants and their coachers who voluntarily took part in the present study, we also want to express our deepest appreciation and many thanks! Without their cooperation and supports, this study would not able to accomplish.

\section{References}

[1] No name. (2016). Badminton Research Paper. http://www.essayempire.com/ customessay/health-research-papers/sportsresearch-paper-topics/7126.html Retrieved from January 18, 2017.

[2] BWF. (2016). https://en.wikipedia.org/wiki/Badminton_World_Federation, 2016. Retrieved from December 5, 2016

[3] Wikipedia. (2016a). Summer Olympic Games. https://en.wikipedia.org/wiki/Summer_Olympic_Games

[4] Clement, B. (2004). Badminton second to soccer in participation. http://sports.espn.go.com/oly/summer04/badminton/ news/story? id=1845228 Retrieved from January 3, 2017.

[5] Phomsoupha, M., \& Laffaye, D. (2002). The science of badminton: Game characteristics, anthropometry, physiology, visual fitness and biomechanics. Sports Medicine, 45(4), 473-495.

[6] Bakar, W.A., Abas, W., \& Rambely, A.S. (2008). Research on Badminton Games: Past and Present. The $4^{\text {th }}$ Kuala Lumpur International Conference on Biomedical Engineering 2008; Volume 21 of the series IFMBE Proceedings, 22-26.

[7] Feng, K.S. (2014). Badminton Research - Badminton back to be emerging sport not impossible. https://castleke2012.wordpress. com/2014/02/24/badminton-research-badminton-back-to-be-emerging-sport-not-impossible/ Retrieved from January 8, 2017.

[8] Cox, R.H. (2011). Sport Psychology: Concepts and Application. Brown \& Benchmark, Dubuque.

[9] Devine, R., \& Lepisto, L. (2005). Analysis of the healthy lifestyle consumer. Journal of Consumer Marketing, 22, 275-283. http://dx.doi.org/10.1108/07363760510611707;:sep: Retrieved from January 13, 2017.

[10] Smith A.L., Balagurer I., \& Duda J.L. (2006). Goal orientation profile differences on perceived motivational climate, perceived peer relationships, and motivation-related responses of youth athletes. Journal of Sports Sciences, 24(12), 1315-1327.

[11] Zeng, Z.H., Cynarski, W.J., Baatz, S. \& Shawn, P.J. (2015). A study of Taekwondo Students' Motivation from New York. World Journal of Education; 5(5), 51-63. http://dx.doi.org/10.5430/wje.v5n5p51.

[12] Miguel, C., \& Machar, M.R. (2007). Motivation in tennis, British Journal of Sports Medicine, 41(11), 769-772. DOI: 10.1136/bjsm.2007.036285

[13] Ryan, R.M., \& Deci, E.L. (2000). Self-determination theory and the facilitation of intrinsic motivation, social development, and well-being. American Psychologist, 55, 68-78. http://psycnet.apa.org/doi/10.1037/0003-066X.55.1.68 Retrieved from December 18, 2016.

[14] Harter, S. (1981). A new self-report scale of intrinsic versus extrinsic orientation in the classroom: Motivational and informational components. Developmental Psychology, 17, 300-312. http://dx.doi.org/10.1037/0012-1649.17.3.300 Retrieved from January 10.

[15] Pintrich, P.R., \& Schunk, D. (2002). Motivation in education: Theory, research and applications (Second ed.). Upper Saddle River, NJ: Prentice-Hall.

[16] Breese, H.P. (1998). Participation motivation in ITFNZ Taekwon-Do: A study of the central districts region. Massey University, NZ.

[17] Ryan, R.M., Frederick, C.M., Lepes, D., Rubio, D., \& Sheldon, K.S. (1997). Intrinsic motivation and exercise adherence. International Journal of Sports Psychology, 28, 355-354.

[18] Jiangsu Nanjing secondary school badminton championship (2014). http://nj12cz.net/newss.asp?id=190 Retrieved from December $15,2016$.

[19] Wikipedia. (2016b). https://en.wikipedia.org_Badminton_players_from_Jiangsu Retrieved from December 9, 2016.

[20] Jiangsu.net. (2017). http://www.jiangsu.net/main/ intro/php, 2017 Retrieved from January 3, 2017.

[21] Zeng, Z.H. \& Xie L.S. (2015). A Study of Youth Tennis Players' Motivation in Suzhou; Research Quarterly for Exercise and Sport, Supplement, 86(2), Published online: 27 Jul 2015.

[22] Child, D. (1990). The essentials of factor analysis, second edition. London: Cassel Educational Limited. 
[23] Statistics Analysis Software for Mac and Windows. (2016). https://www.jmp.com/en_us/offers/statistical-analysis-software.html? utm_campaign=td70114000002KZJq\&utm_source=google\&utm_medium=cpc\&utm_term $=$ statistical\%20analysis\%20software

[24] Khan, Z., Haider, Z., \& Ahmed, N. (2011). Gender difference in achievement motivation of intervarsity level badminton players. Journal of Physical Education and Sport, 11(3), 255-258.

[25] Chinese National Middle School Games (2016). http://www.moe.edu.cn/publicfiles/business/htmlfiles/moe/s3276/201309/ 157501.html

[26] Chinese National Collegiate Games (2016). https://zh.wikipedia.org/wiki/\%E7\%AC\%AC\%E5\%8D\%81\%E5\%B1\% 8A\%E5\%85\%A8\%E5\%9B\%BD\%E5\%A4\%A7\%E5\%AD\%A6\%E7\%94\%9F\%E8\%BF\%90\%E5\%8A\%A8\%E4\%BC\%9A 